\title{
The Effect of Using Combined Oral Ethinyl Estradiol and Levonorgestrel in the Resolution of Menstrual Pattern Disorder and Functional Ovarian Cyst
}

\author{
Najlaa Saadi Ismael* ,Sana Jafar Mohamed** ,Maha Atout*** ,Qutaiba Ahmed Al Khames Aga* ,Sura

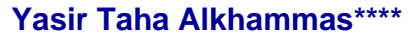 \\ *Philadelphia University, Faculty of Pharmacy ,Amman, Jordan ,**Alkansa'a Teaching Hospital, Mousl, Iraq, \\ ***Philadelphia University, Faculty of Nursing ,Amman, Jordan ,"Philadelphia University, Faculty of Pharmacy, \\ ${ }_{\star \star \star *}$ Fifth Year Student, Philadelphia University, Faculty of Pharmacy ,Amman, Jordan \\ Correspondence: nsaadi@philadelphia.edu.jo
}

(Ann Coll Med Mosul 2019; 41 (2):190-196).

Received: $7^{\text {th }}$ Oct. 2019; Accepted: $13^{\text {th }}$ Oct.2019.

\begin{abstract}
Objectives: To evaluate the usefulness of combined oral contraceptives (ethinyl estradiol and levonorgestrel) in resolving menstrual pattern disorder in reproductive-age women with a functional ovarian cyst in Iraq.

Method: A longitudinal (before and after), interventional study was used. Data were collected at a single obstetrics and gynaecology outpatient clinic in Mosul City, Iraq. Participants: A sample of 96 women aged between 15 and 45 years participated in the study. Participants diagnosed with ovarian cysts were treated using an oral administration of contraceptive pills (combination of ethinyl estradiol, $0.03 \mathrm{mg}$, and levonorgestrel, $0.15 \mathrm{mg}$ ) on a daily basis for a treatment duration of 2 months. The Outcome Measures are Menstrual pattern disorders (dysmenorrhea, irregular menstrual cycle, and amenorrhea) and cyst dimensions were recorded.

Results: After one therapy cycle, a statistically significant disappearance of menstrual pattern disorder was observed $(p=0.000)$. Cyst resolution was observed in $89.58 \%$ of the patients $(n=86)$, while mean ovarian cyst size fell from $4.452 \pm 1.0603 \mathrm{~cm}$ at the start of therapy to $0.451 \pm 1.5613 \mathrm{~cm}(\mathrm{p}=0.000) .5$ of the 10 persistent cysts disappeared after the second cycle (2 months after the start of therapy) and complete cyst resolution was $94.8 \%(n=91)$ after two cycles. This indicated a further significant reduction of mean ovarian cyst size to $0.335 \pm 1.4684 \mathrm{~cm}$. However, no significant difference was observed between mean cyst size in the first and second months of treatment $(p=0.329)$.

Conclusion: Combined oral contraceptives (ethinyl estradiol and levonorgestrel pills) are effective in relieving dysmenorrhea, irregular menstrual cycle, and amenorrhea. They also hasten the disappearance of functional ovarian cysts, and are associated with high rates of success in patients with functional ovarian cysts.
\end{abstract}

Keywords: Combined oral contraceptives pill's, functional ovarian cysts.

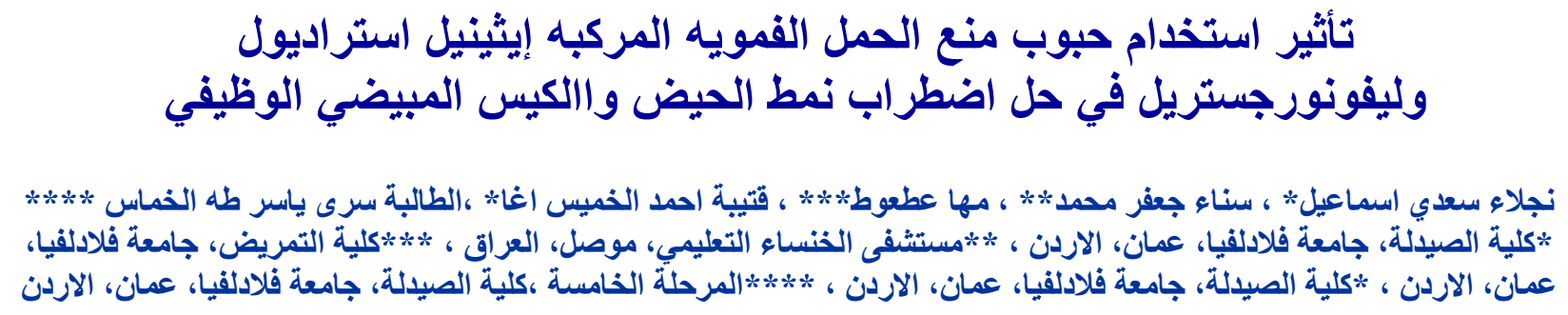


الهـف من الدراسةة: تهدف هذه الدر اسة إلى تقييم فائدة حبوب منع الحمل الفموية المركبة (إيثينيل استر اديول وليفونورجستريل) في الإني

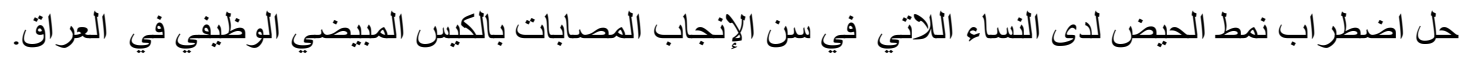

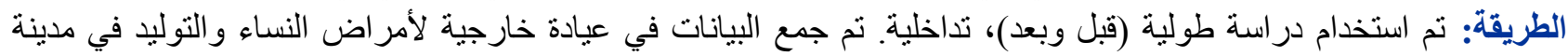

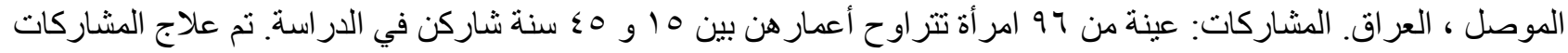

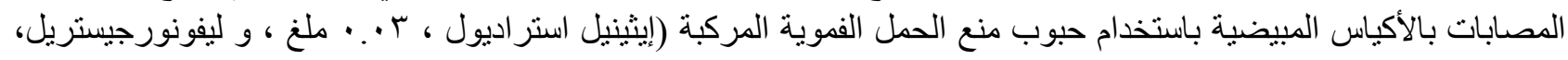

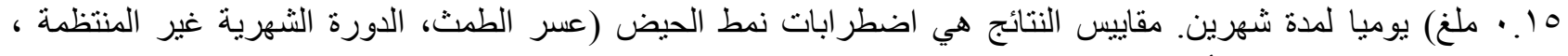
و انقطاع الطمث) وتم تسجيل أبعاد الكيس.

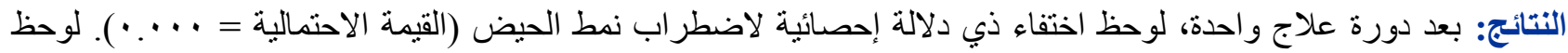

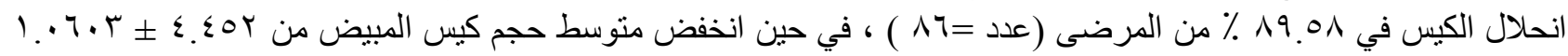

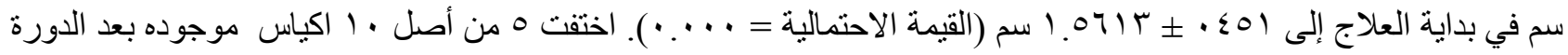

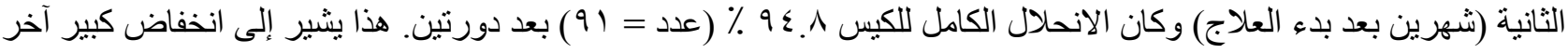

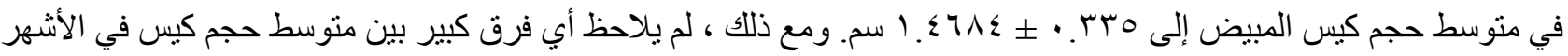

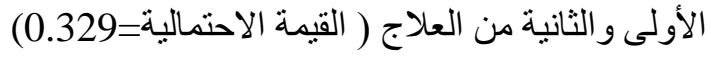

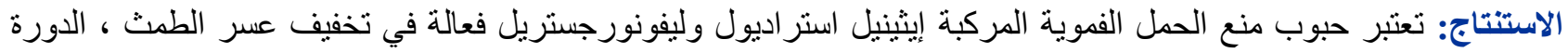

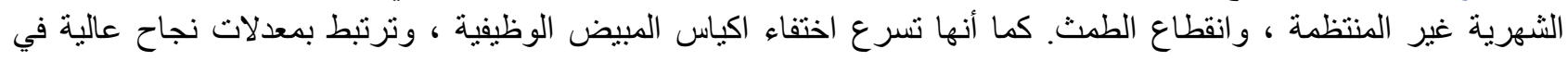
المريضات اللاتي يعانين من الاكياس المبيضية الوظيفية.

الكلمات المفتاحية: حبوب منع حمل فمويه مركبه ، أكياس مبيض وظيفية.

\section{INTRODUCTION}

D ue to the emergence of periodic physical assessments and ultrasonography, the diagnosis of ovarian cysts, which are classified as fluid-filled sacs located within an ovary containing either a liquid or semiliquid substance, has become a more straightforward task1,2. Almost all ovarian cysts identified in reproductive-age females are physiological (functional) rather than pathological, a category which can be subdivided into the following two types: firstly, follicular cysts; and secondly, cystic corpus luteum3. In pre-and post-menopausal females, Greenlee, Kessel4, found that reports of ovarian cyst prevalence vary significantly from $8 \%$ to $18 \%$, while Grimes, Jones5, identified ovarian cysts as a fundamental gynaecological concern for reproductive-age females globally.

In terms of the cause of follicular cysts, the evidence indicates that over the menstrual cycle's early proliferative phase, a collection of follicles grows in response to the secretion of folliclestimulating hormone and luteinising hormone. In turn, a single follicle emerges as dominant, continually expanding until it reaches around 2.5 $\mathrm{cm}$ to $3.0 \mathrm{~cm}$. In the event that fluids in a follicle other than the dominant one are not resorbed and continually grow, this is classified as a follicular cyst. As visualised by ultrasonographic assessment, follicular cysts are characterised by thin walls, their vascular nature, and a single chamber, which contains anechoic fluid which leads to posterior acoustic enhancement6. Follicular cysts can range from $3 \mathrm{~cm}$ to $8 \mathrm{~cm}$, and when these cysts grow rapidly, rupture, or haemorrhage, this can produce discomfort and pain. The formation and slow involution of the corpus luteum takes place 6 weeks after ovulation, the latter process lasting the course of the menstrual cycle until menstruation. In certain cases, fluid may remain and continue to gather inside the corpus luteum, thus giving rise to a corpus luteal cyst. According to Dupuis and Kim7 , corpus luteal cysts are dissimilar to follicular cysts in that they are characterised by comparatively thick, irregular walls.

While public health initiatives such as screening and period physical assessments have improved diagnosis rates for ovarian cysts, along with the 
development of ultrasonography2, surgical interventions are necessary for the removal of persistent, painful, or large cysts, which can in turn lead to oophorectomy5. As noted by Bottomley and Bourne8, it is worth emphasising that the majority of ovarian cysts are identified by chance, typically as a result of routine pelvic or ultrasonographic evaluation. Despite the fact that simple ovarian cysts cannot be considered precursor lesions to malignant ovarian cancer, it is necessary to conduct effective assessments to confirm the lack of solid or papillary structures prior to the diagnosis of an ovarian cyst as a simple ovarian cyst. Although progression to malignancy is rare, follow-up examinations are essential9,10.

The combined oral contraceptive pill (COCP), frequently referred to as the birth control pill (or simply "the pill"), contains small doses of a progestin and an oestrogen-like hormone, comparable to the naturally-occurring progesterone and oestrogen produced by the female body. The COCP is regularly administered as a preventive agent, and according to some healthcare professionals, the medication represents an effective treatment agent for ovarian cysts 10 . Due to this, birth control pills were introduced into joint clinical practice at the beginning of the 1970s5. As noted by Bottomley and Bourne8, certain ovarian cysts are linked to both acute and chronic complications, and so the role played by the COCP as a treatment agent for gynaecological conditions is important to recognise 11.

Dysmenorrhea refers to the uncomfortable cramping that originates within the uterus over the course of menstruation. The condition is a prevalent cause of pelvic pain and menstrual disorder, and it stems from the secretion of prostaglandins which induce uterine muscle contractions12. In the case of primary dysmenorrhea, the condition is classified as uncomfortable menses for females with healthy pelvic anatomy, and it typically begins during adolescence. Contrastingly, secondary dysmenorrhea, which can start long after menarche, is classified as menstrual pain arising from a health condition (e.g., pelvic inflammatory disease, intrauterine devices, endometriosis, infertility issues, ovarian cysts, adenomyosis, irregular cycles, uterine myomas, cervical stenosis, or intrauterine adhesions)13. According to Sanghera, Roberts14, certain contraceptive medications containing hormones are associated with reduction of dysmenorrhea.

The landscape of public health in Iraq, a developing country, is affected by a range of political considerations. Nevertheless, the literature is scarce in Iraq regarding the utility of combined oral contraceptive administration for the improvement of menstrual pattern disorder for reproductive-age females suffering from functional ovarian cysts. Therefore, this study evaluates the usefulness of combined oral contraceptives (ethinyl estradiol and levonorgestrel) in resolving menstrual pattern disorder in women of reproductive age with a functional ovarian cyst in Iraq.

\section{PATINTS AND METHODS Design}

Alongitudinal(before and after study) interventional study design was adopted to evaluate the usefulness of combined oral contraceptives(ethinyl estradiol and levonorgestrel) in menstrual pattern disorder for reproductive-age women with a functional ovarian cyst in Mosul City, Iraq.

\section{Selection and Description of Participants}

This study was conducted at a single obstetrics and gynaecology outpatient clinic in Mosul City, Iraq. A convenience sample comprising 105 reproductive-age females was recruited for the study. Only 96 women were eligible and willing to participate over the study period, with a response rate of $90 \%$. The inclusion criteria for the participants were as follows:(a) Reproductive age (15-45 years); (b) Currently suffering from dysmenorrhea, irregular menstrual cycle, or amenorrhea; (c) Diagnosed with ovarian cysts; (d) No evidence of renal, liver, or cardiovascular disease; (e) Not hypertensive; (f) Not receiving any medication at the time of the study; and (g) Neither a smoker nor an alcoholic.

\section{Technical Information}

Data were collected between 1 December 2017 and 1 December 2018. The participants were recruited during visits to an obstetrics and gynaecology outpatient clinic in Mosul City, Iraq. The diagnosis of prospective participants' ovarian 
cysts took place over the course of the following phases: firstly, a physical assessment was performed to facilitate a clinical diagnosis; and secondly, transvaginal ultrasonography was performed as expectant management for two months with no resolution of the gynaecological issue and no disappearance of the ovarian cyst. Combined oral contraceptive pills(COCPs) containing ethinyl estradiol $(0.03 \mathrm{mg})$ and levonorgestrel $(0.15 \mathrm{mg})$ were administered on a daily basis for a 2-month period. Over the treatment duration, patients received baseline (pretreatment) and monthly ultrasonography assessments involving transvaginal ultrasound to assess changes in size, resolution, or complications.

\section{Ethics}

The purpose of the study was explained to each prospective participant in order to ensure voluntary and informed consent. Further to this, information sheets and recruitment pamphlets relating to the details of the study were distributed during the meeting. Prospective participants were assured that their participation would have no effect on their treatment, and that they would not be exposed to harm.

\section{Statistical Analysis}

Data were analysed using the Statistical Package for Social Sciences (SPSS) (version 25). Descriptive statistics were applied to determine the mean and standard deviation $(M \pm S D)$ for quantitative data, while non-parametric variables were expressed as counts and percentages. The McNemar test was used to test significance for non-parametric variable, while $X$ was used to test significance for quantitative variables. A probability value ( $p$ value) of less than 0.05 was considered statistically significant.

\section{RESULTS}

Table 1 provides an overview of the participants' demographic characteristics. The participants, all female, were aged 15-45 (30.75 \pm 8.36$)$.

Most participants were married $(90.6 \%)$, relatively few were single $(7.3 \%)$, and only $2.1 \%$ were widowed. Additionally, the majority of the detected cysts were simple and unilateral with mean $4.45 \pm$ 1.06 .
Table 1: Participants' demographic characteristics

Total participants $(n=96)$

\begin{tabular}{l|l}
\hline Age (Years) & Mean \pm SD \\
& $30.75 \pm 8.36$ \\
Marital status (count and percentage) \\
\hline Single & $7(7.3 \%)$ \\
\hline Married & $87(90.6 \%)$ \\
\hline Widowed & $2(2.1 \%)$
\end{tabular}

As shown in Table 2, cysts were categorised based on their size, revealing that most $(n=72)$ were unilateral with a diameter of $3-5 \mathrm{~cm}$. 24 cysts were more than $5 \mathrm{~cm}$ in diameter.

Table 2: Characteristics of ovarian cysts by age group.

\begin{tabular}{|c|c|c|c|c|c|}
\hline \multirow{4}{*}{$\begin{array}{c}\text { Age } \\
\text { Group }\end{array}$} & \multicolumn{3}{|c|}{ Location } & \multirow{2}{*}{\multicolumn{2}{|c|}{ Size $(\mathrm{cm})$}} \\
\hline & \multicolumn{3}{|c|}{ Unilateral/ } & & \\
\hline & \multicolumn{2}{|c|}{ Laterality } & Bilateral & \multirow[b]{2}{*}{$3-5 \mathrm{~cm}$} & \multirow[b]{2}{*}{$>5 \mathrm{~cm}$} \\
\hline & Right & left & & & \\
\hline $\begin{array}{l}15-25 \\
\text { years }\end{array}$ & 7 & 18 & & 19 & 6 \\
\hline $\begin{array}{l}26-36 \\
\text { years }\end{array}$ & 10 & 31 & & 31 & 10 \\
\hline $\begin{array}{l}37-45 \\
\text { years }\end{array}$ & 16 & 13 & 1 & 22 & 8 \\
\hline Total & 33 & 62 & 1 & & \\
\hline
\end{tabular}

Table 3: Effect of oral contraception on gynaecological condition.

\begin{tabular}{lcll}
\hline $\begin{array}{l}\text { Gynaecological } \\
\text { Condition }\end{array}$ & $\begin{array}{l}\text { Before } \\
\text { reatment }\end{array}$ & $\begin{array}{l}\text { After } \\
\text { Treatment }\end{array}$ & P value \\
\hline Dysmenorrhea & $43(44.8 \%)$ & 1 & $0.000^{*}(\mathrm{~s})$ \\
amenorrhea & $36(37.5 \%)$ & 1 & $0.000^{*}(\mathrm{~s})$ \\
Irregular & & & \\
Menstrual & $63(65.6 \%)$ & 1 & $0.000^{*}(\mathrm{~s})$ \\
& & & \\
\hline
\end{tabular}

* McNemar test 
The mean difference is significant at the 0.05 level

Forty three participants (44.8\%) presented with dysmenorrhea, 36 (37.5\%) had menorrhea, and 63 (65.6\%) suffered from irregular menstrual cycles. All participants received medical treatment with COCPs (containing ethinyl estradiol, $0.03 \mathrm{mg}$, and levonorgestrel, $0.15 \mathrm{mg}$ ) table 3 .

After a single therapy cycle, a statistically significant disappearance was observed for menstrual pattern disorder (including dysmenorrhea, irregular menstrual cycle, and amenorrhea) $(p=0.000)$. Ovarian cyst resolution was observed in 86 (89.58\%) of the 96 patients Table 4 .

Table 4: Disappearance rates of functional ovarian cysts in management in patients for terminal period

\begin{tabular}{ll}
\hline Outcome & Count and Percentage \\
\hline $\begin{array}{l}\text { Disappearance } \\
\text { after one therapy cycle }\end{array}$ & $\mathbf{8 6}(\mathbf{8 9 . 5 8 \% )}$ \\
\hline $\begin{array}{l}\text { Disappearance } \\
\text { after two therapy cycles }\end{array}$ & $\mathbf{5 ( 5 . 2 \% )}$ \\
Persistence of cyst & $\mathbf{5 ( 5 . 2 \% )}$ \\
\hline
\end{tabular}

Mean ovarian cyst size dropped from $4.452 \pm$ $1.0603 \mathrm{~cm}$ at the start of therapy to $0.451 \pm 1.5613$ after therapy $(p=0.000)$. 5 of the 10 persistent cysts disappeared after the second cycle (2 months after start of therapy), and complete cyst resolution was observed for 91 participants (94.8\%) after two cycles. The mean significant reduction for ovarian cysts was $0.335 \pm 1.4684 \mathrm{~cm}$. However, no significant difference was observed between mean cyst sizes in the first and second months of treatment $(p=0.329)$ Tables 5,6 , and 7 .

Table 5: Difference in ovarian cyst size before and after one month of treatment

\section{Ovarian}

$\begin{array}{lll}\text { Cyst Size } & \text { Mean } \pm \text { SD } & \text { P value } \\ \text { Number of } & \end{array}$

Patients (96)

\begin{tabular}{lll}
\hline $\begin{array}{l}\text { Ovarian Cyst } \\
\text { Size Before Treatment }\end{array}$ & $4.452 \pm 1.0603$ & \\
$\begin{array}{l}\text { Ovarian Cyst Size } \\
\text { After One Month }\end{array}$ & $0.000^{*}(\mathrm{~s})$ \\
of Treatment & & \\
\hline
\end{tabular}

Based on estimated marginal means

*The mean difference is significant at the 0.05 level

Adjustment for multiple comparisons: Bonferroni.

Table 6: Difference in ovarian cyst size before and after two months of treatment

\begin{tabular}{lll}
\hline $\begin{array}{l}\text { Ovarian Cyst Size } \\
\text { Number of Patients (96) }\end{array}$ & Mean \pm SD & P value \\
\hline $\begin{array}{l}\text { Ovarian Cyst Size } \\
\text { Before Treatment }\end{array}$ & $4.452 \pm 1.0603$ & \\
\hline $\begin{array}{l}\text { Ovarian Cyst Size } \\
\text { After Two Months } \\
\text { of Treatment }\end{array}$ & $0.335 \pm 1.4684$ & 0.000 \\
\hline
\end{tabular}

Based on estimated marginal means

* The mean difference is significant at the $\cdot .05$ level

Adjustment for multiple comparisons: Bonferroni

Table 7: Difference in ovarian cyst size before and after one and two months of treatment, respectively

\begin{tabular}{lll}
\hline $\begin{array}{l}\text { Ovarian Cyst Size } \\
\text { Number } \\
\text { of Patients (96) }\end{array}$ & Pean \pm SD & \\
\hline $\begin{array}{l}\text { Size of Ovarian Cyst } \\
\text { After One Month }\end{array}$ & $0.451 \pm 1.5613$ & \\
$\begin{array}{l}\text { of Treatment } \\
\text { Size of Ovarian Cyst }\end{array}$ & & \\
After Two Month & 0.329 & \\
of Treatment & & \\
\hline
\end{tabular}

Based on estimated marginal means

${ }^{*}$ The mean difference is significant at the 0.05 level

Adjustment for multiple comparisons: Bonferroni

For the 5 cysts which were persistent after 2 months of COCP treatment, surgical intervention was undertaken using an open technique (laparotomy) or a minimally invasive technique (laparoscopy). Small incisions were applied, and in the course of operating, pathological cysts were identified in each case. 


\section{DISCUSSION}

It is well-documented that due to the administration of COCPs, cyst incidence has fallen. This is because COCPs suppress ovulation, thus meaning that eggs are not released from the ovaries $^{12}$. With this in mind, healthcare professionals began to treat cysts with COCPs, understanding that this would hasten the disappearance of the condition ${ }^{5}$. It is also worth noting that because COCP administration abbreviated mean cyst duration, they could be used as valuable pharmacological agents in managing accompanying menstrual conditions ${ }^{15}$. According to Bottomley and Bourne ${ }^{8}$, it is possible to safeguard against recurrent cyst rupture or haemorrhage with COCPs administration, and early COCPs were Inked to a lower incidence of functional ovarian cysts ${ }^{16}$.

The evidence shows that morbidity and quality of life fall and rise, respectively, with the use of COCPs. One of the principal ways to account for this finding is that COCPs reduce the incidence of ovarian cysts, and as such, prevent the emergence of painful conditions such as menstrual cramps, menstrual bleeding issues, ovulation pain, and endometriosis symptoms(e.g., pelvic pain). As emphasised by Brynhildsen ${ }^{17}$, COCPs can be used to treat dysmenorrhea, hirsutism, and acne vulgaris. More specifically, the levonorgestrelreleased intrauterine system is a reversible way in which to treat dysmenorrhea and menorrhagia ${ }^{14}$. This study's findings are also consistent with Cochrane reviews addressing the impact of COCPs on functional ovarian cyst resolution. The reviews reported that no significant differences could be observed between therapeutic interventions in functional ovarian cysts and no intervention, noting that cyst resolution occurs spontaneously in almost all case, irrespective of treatment. Nevertheless, it is worth emphasising that these trials included relatively small sample sizes, and a high level of heterogeneity was observed $^{5,16}$.

Consistent with Bernardi $\mathrm{M}$ ea al ${ }^{12}$, this study attests to the statistically significant impact that COCPs administration has on dysmenorrhea, irregular menstrual cycle, and amenorrhea in reproductive-age females suffering from functional ovarian cysts. As reported elsewhere in the literature, COCPs bring rapid relief and regulatory benefits to the pain associated with menstruation, including irregular bleeding and uncomfortable periods, and they can be used to treat symptomatic menorrhagia and primary dysmenorrhea ${ }^{11,18,19}$. The results presented in this study are in agreement with this evidence, and at the same time, show that COCPs can hasten the complete resolution of functional ovarian cysts. However, it is worth noting that several months of watchful waiting could be necessary for the achievement of similar success rates, and this could represent a viable alternative to oral contraceptive therapy. In addition, surgical evaluation of persistent ovarian cysts is essential.

This study's limitations, including its use of the convenience sampling technique and the method used to estimate the sample size, could have affected the generalisability of the findings to other settings. Therefore, future studies should be pursued in which larger sample sizes are utilised. At the same time, probability sampling techniques should be employed to ensure that the study population is representative of the target population. Finally, to determine whether statistically significant differences exist between watchful waiting of cysts and active pharmacological intervention in cyst development through COCP administration, future studies should consider employing control groups in the context of a randomised controlled trial.

\section{CONCLUSION}

Combined oral contraceptives (ethinyl estradiol and levonorgestrel pills) are effective in relieving dysmenorrhea, irregular menstrual cycle, and amenorrhea. They also hasten the disappearance of functional ovarian cysts, and are associated with high rates of success in patients with functional ovarian cysts.

\section{DECLARATION OF INTEREST}

\section{Statement}

The research has no conflict of interest and is not funded from any source.

\section{Acknowledgments}

The authors wish to express their profound gratitude to the women who participated in this study who so willingly gave their time and were crucial to the data collection process. This study 
would not have been possible without their cooperation.

\section{REFERENCES}

1.Al Zahidy ZA. Causes and Management of Ovarian Cysts. The Egyptian Journal of Hospital Medicine. 2018;70(10):1818-22.

2.Knight JA, Lesosky $\mathrm{M}$, Blackmore $\mathrm{KM}$, et al. Ovarian cysts and breast cancer: results from the Women's Contraceptive and Reproductive Experiences Study. Breast cancer research and treatment. 2008;109(1):157-64.

3.Abduljabbar HS, Bukhari YA, Al Hachim EG, et al. Review of 244 cases of ovarian cysts. Saudi medical journal. 2015;36(7):834-8.

4.Greenlee RT, Kessel B, Williams CR, et al. Prevalence, incidence, and natural history of simple ovarian cysts among women $>55$ years old in a large cancer screening trial. American journal of obstetrics and gynecology. 2010;202(4):373.e1-9.

5.Grimes DA, Jones LB, Lopez LM, et al. Oral contraceptives for functional ovarian cysts. . Cochrane Database of Systematic Reviews 2014(4):CD006134.

6.Jeong $Y$, Outwater $E$, Kang $H$. Imaging evaluation of ovarian masses. Radiographics. 2000;20:1445-70.

7.Dupuis CS, Kim YH. Ultrasonography of adnexal causes of acute pelvic pain in pre-menopausal non-pregnant women. Ultrasonography (Seoul, Korea). 2015;34(4):258-67.

8.Bottomley C, Bourne T. Diagnosis and management of ovarian cyst accidents. Best practice \& research Clinical obstetrics \& gynaecology. 2009;23(5):711-24.

9.Glanc P, Benacerraf B, Bourne $T$, et al. First International Consensus Report on Adnexal Masses: Management Recommendations. Journal of ultrasound in medicine : official journal of the American Institute of Ultrasound in Medicine. 2017;36(5):849-63.

10.Grimes DA, Jones LB, Lopez LM, et al. Oral contraceptives for functional ovarian cysts. The Cochrane database of systematic reviews. 2011(9):Cd006134.

11.Carey MS, Allen RH. Non-contraceptive uses and benefits of combined oral contraception. The Obstetrician \& Gynaecologist. 2012;14(4):223-8.
12.Bernardi M, Lazzeri L, Perelli F, et al .Dysmenorrhea and related disorders. F1000Research. 2017;6:1645-.

13.Unsal A, Ayranci U, Tozun M, et al. Prevalence of dysmenorrhea and its effect on quality of life among a group of female university students. Upsala journal of medical sciences. 2010;115(2):138-45.

14.Sanghera S, Roberts TE, Barton $\mathrm{P}$, et al. Levonorgestrel-releasing intrauterine system vs. usual medical treatment for menorrhagia: an economic evaluation alongside a randomised controlled trial. PLoS One. 2014;9(3):e91891.

15.lervolino $\mathrm{P}$, Rotondi M, luliano RP et al. Ovarian cysts in adolescence: epidemiologic, clinical and management assessment. Minerva ginecologica. 2001;53(1 Suppl 1):63-6.

16.Grimes DA, Jones LB, Lopez LM, et al. Oral contraceptives for functional ovarian cysts. The Cochrane database of systematic reviews. 2009(2):Cd006134.

17.Brynhildsen J. Combined hormonal contraceptives: prescribing patterns, compliance, and benefits versus risks. Therapeutic advances in drug safety. 2014;5(5):201-13.

18.Latthe P, Mignini L, Gray R, et al. Factors predisposing women to chronic pelvic pain: systematic review. BMJ (Clinical research ed). 2006;332(7544):749-55.

19.Lindh I, Ellstrom AA, Milsom I. The effect of combined oral contraceptives and age on dysmenorrhoea: an epidemiological study. Human reproduction (Oxford, England). 2012;27(3):676-82. 